\title{
The Improved Arrhenius Model with Variable Parameters of Flow Behavior Characterizing for The As-Cast AZ80 Magnesium Alloy
}

\author{
Guo-zheng Quan*, Yu Shi, Chun-tang Yu, Jie Zhou \\ School of Material Science and Engineering, Chongqing University, Chongqing 400044, China
}

Received: August 3, 2012; Revised: December 20, 2012

\begin{abstract}
In order to study the hot working behaviour of as-cast AZ80 magnesium alloy, a series of isothermal upsetting tests with height reduction of 60\% were performed at the temperature range of 523-673 K and the strain rate range of $0.01-10 \mathrm{~s}^{-1}$ on a servo-hydraulic Gleeble- 1500 machine simulator. Based on the regression analysis for Arrhenius type equation of flow stress, the activation energy of deformation was determined to be $Q=168.6606 \mathrm{KJ} \cdot \mathrm{mol}^{-1}$, and material constants $A, n$ and $\alpha$ in the equation also were calculated respectively to predict the peak stress during hot deformation. A $7^{\text {th }}$ order polynomial was used to represent the influence of strain on these parameters (i.e $Q, \ln A, n$ and $\alpha$ ). The Arrhenius equation was further developed by taking account of the effect of strain on the flow stress to describe the flow behavior during the whole experimental temperature and strain rate range. Then comparison between the predicted results and test results shows that the correlation coefficient and average absolute relative error is 0.99 and $6.63 \%$, respectively. The flow stress predicted by developed equation can give an accurate and precise description of the flow behaviour for AZ80 magnesium alloy.
\end{abstract}

Keywords: magnesium alloy, flow stress, activation energy, constitutive equation

\section{Introduction}

Magnesium alloy is one of the lightest structural metallic materials, and it is widely applied in aerospace, automobile and electronic industries for its excellent properties such as high specific strength superior damping characteristics and electromagnetic shielding performance ${ }^{1}$. Magnesium alloy has a hexagonal close-packed crystal structure whose dominant slip system at room temperature is basal slip. The workability of magnesium alloy becomes sufficiently available by thermal activation at the high temperatures due to the workability substantially increasing as additional slip systems ${ }^{2}$. It is obvious that warm or hot working condition offers the chance to improve the workability of magnesium alloy through the activation of the non-basal slip plane.

Constitutive equations are often used to describe the plastic flow properties of the metal and alloys under the prevailing loading conditions, such as forming temperature, degree of deformation, and strain rate. And most of models are various analytical, phenomenological and empirical in nature $^{3}$. A phenomenological approach was proposed by Jonas et al. ${ }^{4}$, in which the flow stress is expressed by the hyperbolic laws in an Arrhenius-type equation. And this equation has been widely used to represent the elevated temperature flow behavior of a range of metals or alloys ${ }^{5-8}$. However, there are some limitations for the Arrhenius-type equation. In recent years, this equation has been improved by considering the special effects of the hot forming parameters (such as activation energy of deformation $Q$, material constants $n$ and $\alpha$, and structure factor $A$ ) to accurately describe and predict the flow stress for the different metals or alloys. Lin et al. proposed a revised hyperbolic sine

*e-mail: quangz3000@sina.com constitutive equation, in which the influence of strain was incorporated by considering the effect of strain to predict the flow stress of $42 \mathrm{CrMo}$ steel $^{9-11}$. Later, the improved Arrhenius-type equation was effective for describing the high temperature flow behaviors of cast A356 aluminum alloy $^{12}, 9 \mathrm{Cr}-1 \mathrm{Mo}$ ferritic steel ${ }^{13}$, Ti-6Al-4V alloy ${ }^{14}$, T24 steel ${ }^{15-16}$. However, the hot compression deformation behavior of cast AZ80 magnesium alloys needs further investigating to realize the effect of strain.

Accordingly, in the present study, the true stress-strain curves were obtained in hot compression tests of AZ80 magnesium alloy, which was performed under temperature range of $523-673 \mathrm{~K}$ and strain rate of $0.01-10 \mathrm{~s}^{-1}$. The values of activation energy $Q$, and material constant $A, \alpha$ and $n$ in Arrhenius model were invested by multiple linear regression analysis. And strain was taken into compensation to accurately predict the flow stress which was expressed by parameter $Q$, and material constant $A, \alpha$ and $n$. Meanwhile, constitutive model of AZ80 magnesium alloy, containing temperature, strain rate and strain, was established.

\section{Material and Methods}

The material used in this investigation was commercial as-cast AZ80 magnesium alloy with a diameter of $100 \mathrm{~mm}$ and a height of $325 \mathrm{~mm}$. The chemical compositions of AZ80 magnesium alloy used in this study was (wt \%) Al 8.90, Zn 0.53, Mn 0.20, Si 0.008, Fe 0.004, Cu 0.008, Ni 0.0008, $\mathrm{Mg}$ (balance). Cylindrical specimens with a diameter of $10 \mathrm{~mm}$ and the height of $12 \mathrm{~mm}$ were machined with their cylinder axes parallel to the axial line direction of the bar for the compression experiments which were conducted 
on a computer-controlled, servo-hydraulic Gleeble-1500 machine, in which specimens were heated to the setting temperature at the speed of $1 \mathrm{~K} / \mathrm{s}$, and held at a fixed temperature for $3 \mathrm{~min}$ to ensure uniform starting temperature and decrease the material anisotropy. The specimens were compressed at the temperatures of 523, 573, 623 and $673 \mathrm{~K}$, and the stress rates of $0.01,0.1,1,10 \mathrm{~s}^{-1}$ until the reduction of height is $60 \%$ at the end of the compression tests. And then the specimens were immediately cooled by water quenching to retain the structure obtained at elevated temperatures.

\section{Results and Discussion}

\subsection{Constitutive equation of the peak flow stress}

True stress-strain curves of AZ80 magnesium alloy obtained from hot compression test were shown in Figure 1. It shows the relationship of the flow stress and deformation temperature as well as strain rates for AZ80 magnesium alloy.

The correlation between the hot deformation parameters, such as strain rate, deformation temperature and flow stress can be described by hyperbolic-sine Arrhenius type equation ${ }^{17}$.

$|\dot{\varepsilon}|=A F(|\sigma|) \exp [-Q /(R T)]$

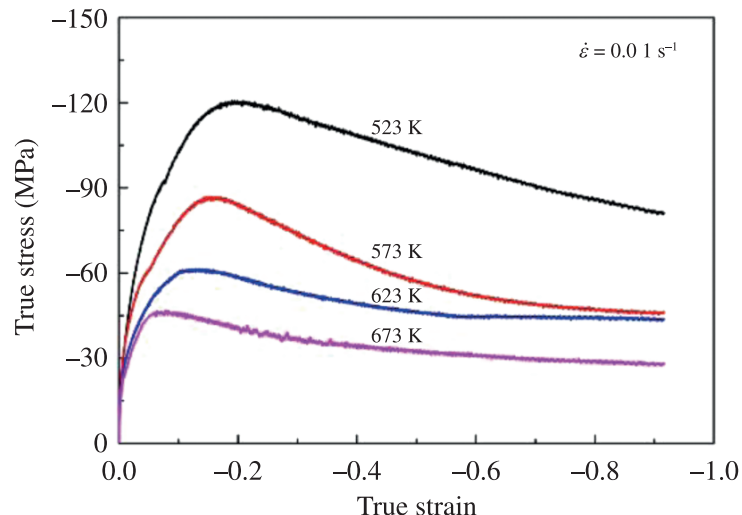

(a)

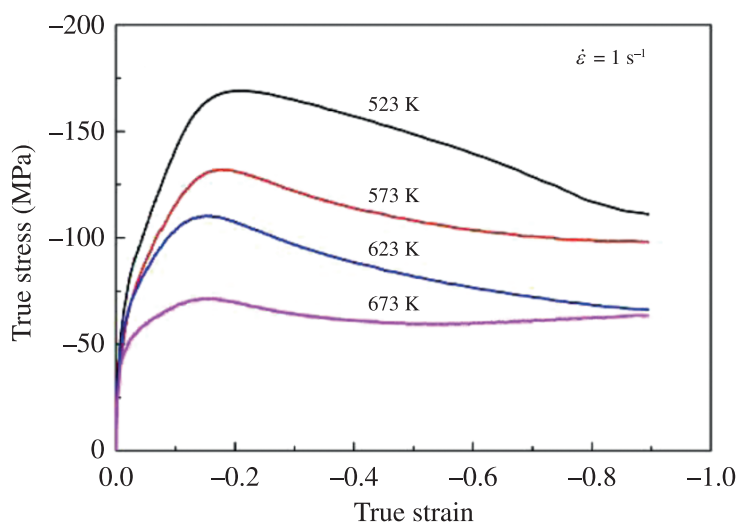

(c)
$F(\sigma)$ is the function of stress, it takes three forms, where,

$F(\sigma)=\left\{\begin{array}{lc}|\sigma|^{n} & \alpha|\sigma|<0.8 \\ \exp (\beta|\sigma|) & \alpha|\sigma|>1.2 \\ {[\sinh (\alpha|\sigma|)]^{n}} & \text { for all }|\sigma|\end{array}\right.$

In which, $A, \alpha, \beta$ and $n$ are the material constants, $\alpha=\beta / \mathrm{n}, \dot{\varepsilon}$ is the strain rate $\left(\mathrm{s}^{-1}\right), R$ is the universal gas constant $\left(8.31 \mathrm{~J} \cdot \mathrm{mol}^{-1} \cdot \mathrm{K}^{-1}\right), T$ is the absolute temperature $(\mathrm{K})$, $Q$ is the activation energy of hot deformation $\left(\mathrm{KJ} \cdot \mathrm{mol}^{-1}\right), \sigma$ is the flow stress (MPa) for given strain.

Also, the effects of the temperatures and strain rate on the deformation behaviors can be represented by ZenerHollomon parameter, $Z$, in an exponent-type equation ${ }^{18}$.

$Z=|\dot{\varepsilon}| \exp [Q /(R T)]$

For the low stress level $(\alpha|\sigma|<0.8)$ and high stress level $(\alpha|\sigma|>1.2$ ), substituting the power low and exponential law into Equation 1, respectively, gives,

$|\dot{\varepsilon}|=A|\sigma|^{n} \exp [-Q /(R T)]$

$|\dot{\varepsilon}|=A \exp (\beta|\sigma|) \exp [-Q /(R T)]$

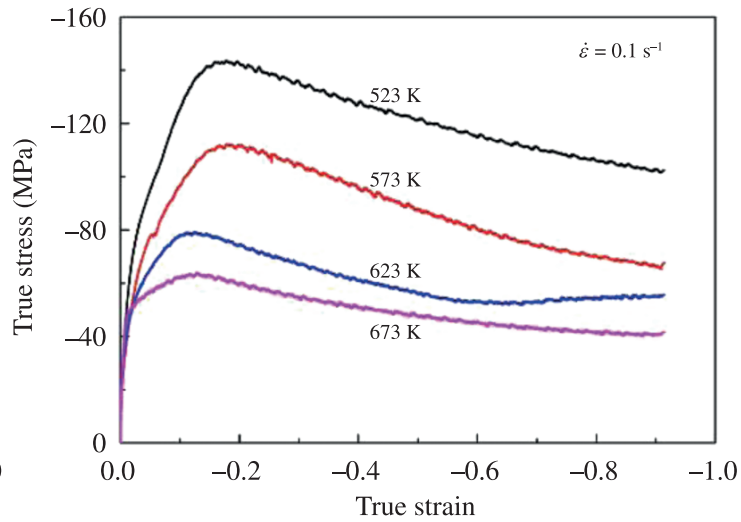

(b)

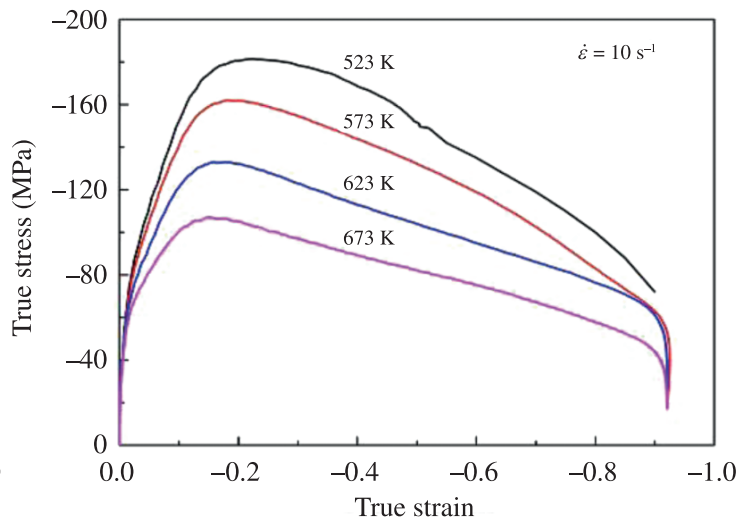

(d)

Figure 1. True strain-stress curves for as-cast AZ80 magnesium alloy under the different deformation temperatures with strain rates of: (a) $0.01 \mathrm{~s}^{-1}$; (b) $0.1 \mathrm{~s}^{-1}$; (c) $1 \mathrm{~s}^{-1}$; (d) $10 \mathrm{~s}^{-1}$. 
Taking the logarithm on both sides of Equation 3 and Equation 4, respectively, gives,

$\ln |\sigma|=\frac{1}{n} \ln |\dot{\varepsilon}|+\frac{1}{n}\left(\frac{Q}{R T}-\ln A\right)$

$|\sigma|=\frac{1}{\beta} \ln |\dot{\varepsilon}|+\frac{1}{\beta}\left(\frac{Q}{R T}-\ln A\right)$

The value of $n$ and $\beta$ can be obtained from the slope of $\ln |\sigma|$ versus $\ln |\dot{\varepsilon}|$ and $|\sigma|$ versus $\ln |\dot{\varepsilon}|$, and $n=\mathrm{d} \ln |\dot{\varepsilon}| / \mathrm{d} \ln |\sigma|$, $\beta=\operatorname{dln}|\dot{\varepsilon}| /|\sigma|$, respectively. Then, substituting the value of the peak stress and corresponding strain rate into the logarithm Equation 5 and Equation 6 gives the relationship between the flow stress and strain rate as shown in Figure 2. It is obvious that linear relationship is observed for each temperature and the slopes are approximated the same with each other. The mean value of all the slope rates is accepted as the inverse of material constant $n$ and $\beta$, thus $n$ and $\beta$ can be obtained as 7.9064 and $0.1023 \mathrm{MPa}^{-1}$, respectively. Then, $\alpha=\beta / n=0.0129 \mathrm{MPa}^{-1}$.

For all the stress level, substituting the hyperbolic law of $F(\sigma)$ into Equation 1 gives,

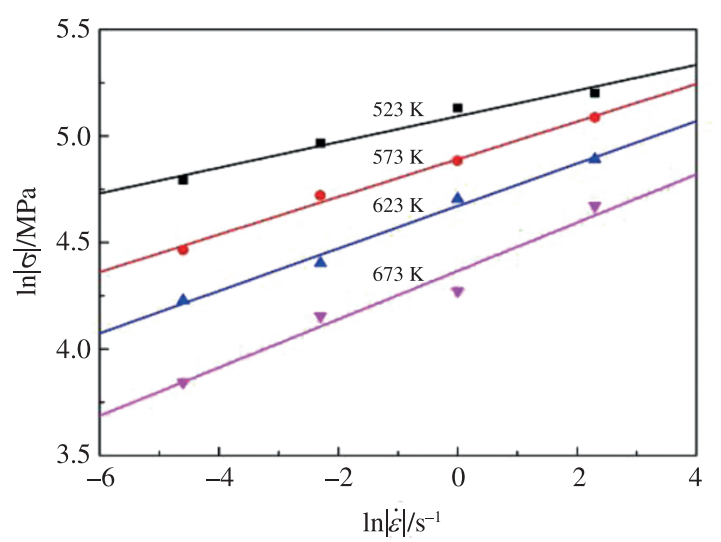

(a)
$|\dot{\varepsilon}|=A[\sinh (\alpha|\sigma|)]^{n} \exp [-Q /(R T)]$

Taking the natural logarithm of both sides of Equation 7 gives,

$\ln |\dot{\varepsilon}|=\ln A+n \ln \sinh [\alpha|\sigma|]-Q / R T$

For the fixed strain rate conditions, there is a linear relationship between $\ln \sinh [\alpha|\sigma|]$ and $1 / T$, differentiating Equation 8 gives,

$Q=R n\{\mathrm{~d}\{\ln [\sinh (\alpha \mid \sigma)]\} / \mathrm{d}(1 / T)\}$

Therefore, the values of different temperatures and peak stresses obtained from each strain rate are substituted into Equation 9, and the value of $Q$ can be derived from the slope of $\ln \sinh [\alpha \mid \sigma]$ versus $1 / T$ by linear fitting method. It is obvious that linear relationship is observed for each strain rate and the slopes are approximated the same with each other, as shown in Figure 3a. The average value under different strain rates of all the slope rates is accepted as activation energy of hot deformation $Q$, thus the value of $Q$

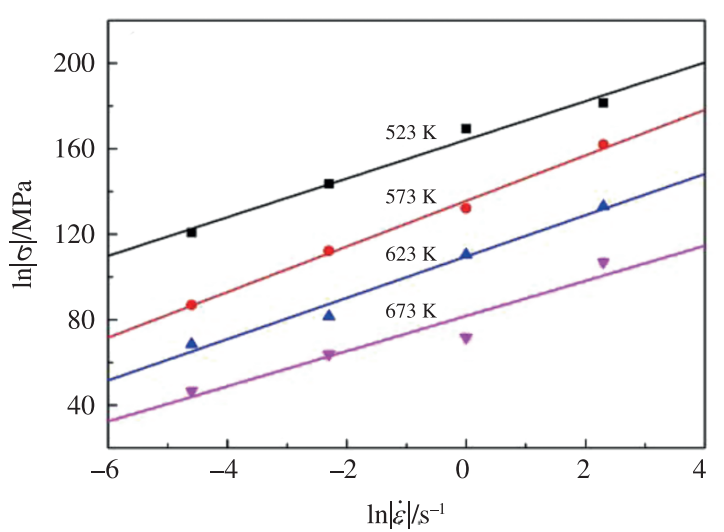

(b)

Figure 2. Relationships between strain rates and peak stresses: (a) $\ln |\dot{\varepsilon}|$ and $\ln |\sigma|$; (b) $\ln |\dot{\varepsilon}|$ and $|\sigma|$.

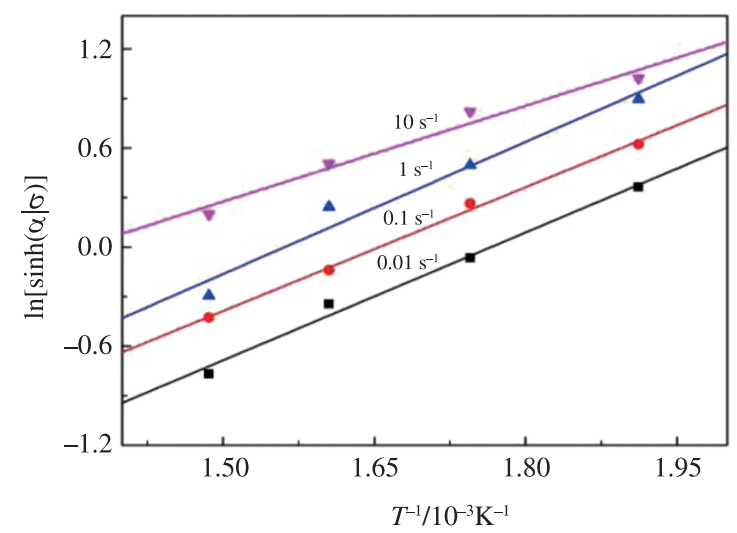

(a)

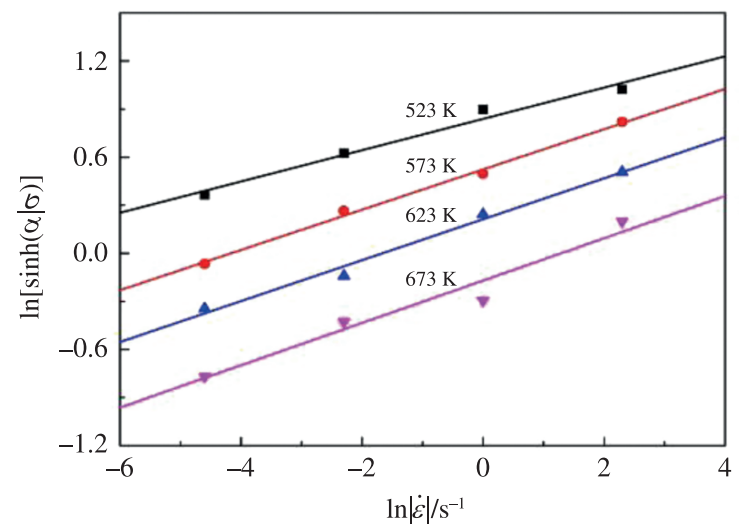

(b)

Figure 3. Relationships between: (a) $\ln \sinh [\alpha|\sigma|]$ and $1 / T$; (b) $\ln \sinh [\alpha|\sigma|]$ and $\ln |\dot{\varepsilon}|$. 
equals $168.6606 \mathrm{KJ} \cdot \mathrm{mol}^{-1}$. Figure 4 shows the flow diagram for determining all parameters in constitutive equation.

And Equation 8 can also be expressed as following:

$\ln \sinh (\alpha|\sigma|)=\frac{1}{n} \ln |\dot{\varepsilon}|+\frac{1}{n}\left(\frac{Q}{R T}-\ln A\right)$

Then, substituting the values of the peak stress at different temperatures and strain rates into Equation 10, the linear relationships between $\ln \sinh [\alpha|\sigma|]$ and $\ln |\dot{\varepsilon}|$ for different temperatures can be obtained as shown in Figure $3 \mathrm{~b}$. It is obvious that the intercept of $\ln \sinh [\alpha|\sigma|]$ versus $\ln |\dot{\varepsilon}|$ plot is the value of $1 / n(Q / R T-\ln A)$, submitting the values of material constants $\alpha, n$ and activation energy $Q$, the value of material constant $A$ is easily to be calculated as $1.729 \times 10^{13} \mathrm{~s}^{-1}, 8.749 \times 10^{12} \mathrm{~s}^{-1}, 7.023 \times 10^{12} \mathrm{~s}^{-1}$, $1.505 \times 10^{13} \mathrm{~s}^{-1}$ for different temperatures respectively.

Substituting Equation 2 into Equation 1, then the flow stress can be written as a function contains Zener-Hollomon parameter in the following equation:

$|\sigma|=\frac{1}{\alpha} \ln \left\{\left(\frac{Z}{A}\right)^{\frac{1}{n}}+\left[\left(\frac{Z}{A}\right)^{\frac{2}{n}}+1\right]^{\frac{1}{2}}\right\}$

The constitutive equation of flow stress for AZ80 magnesium alloy can be express as:

$|\sigma|=\frac{1}{0.0129} \ln \left\{\left(\frac{Z}{A}\right)^{1 / 7.9064}+\left[\left(\frac{Z}{A}\right)^{2 / 7.9064}+1\right]^{1 / 2}\right\}$

\subsection{Compensation of strain}

This model is adopted as a general equation of hot deformation. But this model does not involve the strain on hot deformation behaviour, and it ignores the effects of strain on the flow stress, so it can only represent steady-state stress. In order to promote the practical application of numerical analysis on hot forging and investigate the effect of strain on hot deformation behavior, it is necessary to improve the accuracy of prediction flow stress. So, a set of parameters of $Q, n, A$ and $\alpha$ can be calculated as polynomial function with strain in the range of $0 \sim-0.9$ and the interval of -0.1 using the aforementioned method, as show in Equation 13. The relationship between $Q, n, A, \alpha$ and strain can be polynomial fitting as shown in Figure 5, and the coefficients of the polynomial function can be easily obtained by polynomial fitting method shown in Table 1.

$$
\begin{aligned}
& Q=B_{0}+B_{1} \varepsilon+B_{2} \varepsilon^{2}+B_{3} \varepsilon^{3}+B_{4} \varepsilon^{4}+B_{5} \varepsilon^{5}+B_{6} \varepsilon^{6}+B_{7} \varepsilon^{7} \\
& n=C_{0}+C_{1} \varepsilon+C_{2} \varepsilon^{2}+C_{3} \varepsilon^{3}+C_{4} \varepsilon^{4}+C_{5} \varepsilon^{5}+C_{6} \varepsilon^{6}+C_{7} \varepsilon^{7} \\
& \ln A=D_{0}+D_{1} \varepsilon+D_{2} \varepsilon^{2}+D_{3} \varepsilon^{3}+D_{4} \varepsilon^{4}+D_{5} \varepsilon^{5}+D_{6} \varepsilon^{6}+D_{7} \varepsilon^{7} \\
& \alpha=E_{0}+E_{1} \varepsilon+E_{2} \varepsilon^{2}+E_{3} \varepsilon^{3}+E_{4} \varepsilon^{4}+E_{5} \varepsilon^{5}+E_{6} \varepsilon^{6}+E_{7} \varepsilon^{7}
\end{aligned}
$$

Finally, substituting the polynomial function of $Q, n$, $A$ and $\alpha$, which can be expressed as $b(\varepsilon), c(\varepsilon), d(\varepsilon)$, and $e(\varepsilon)$ respectively into Equation 12 . The Arrhenius type equation of AZ80 magnesium alloy can be developed as following:

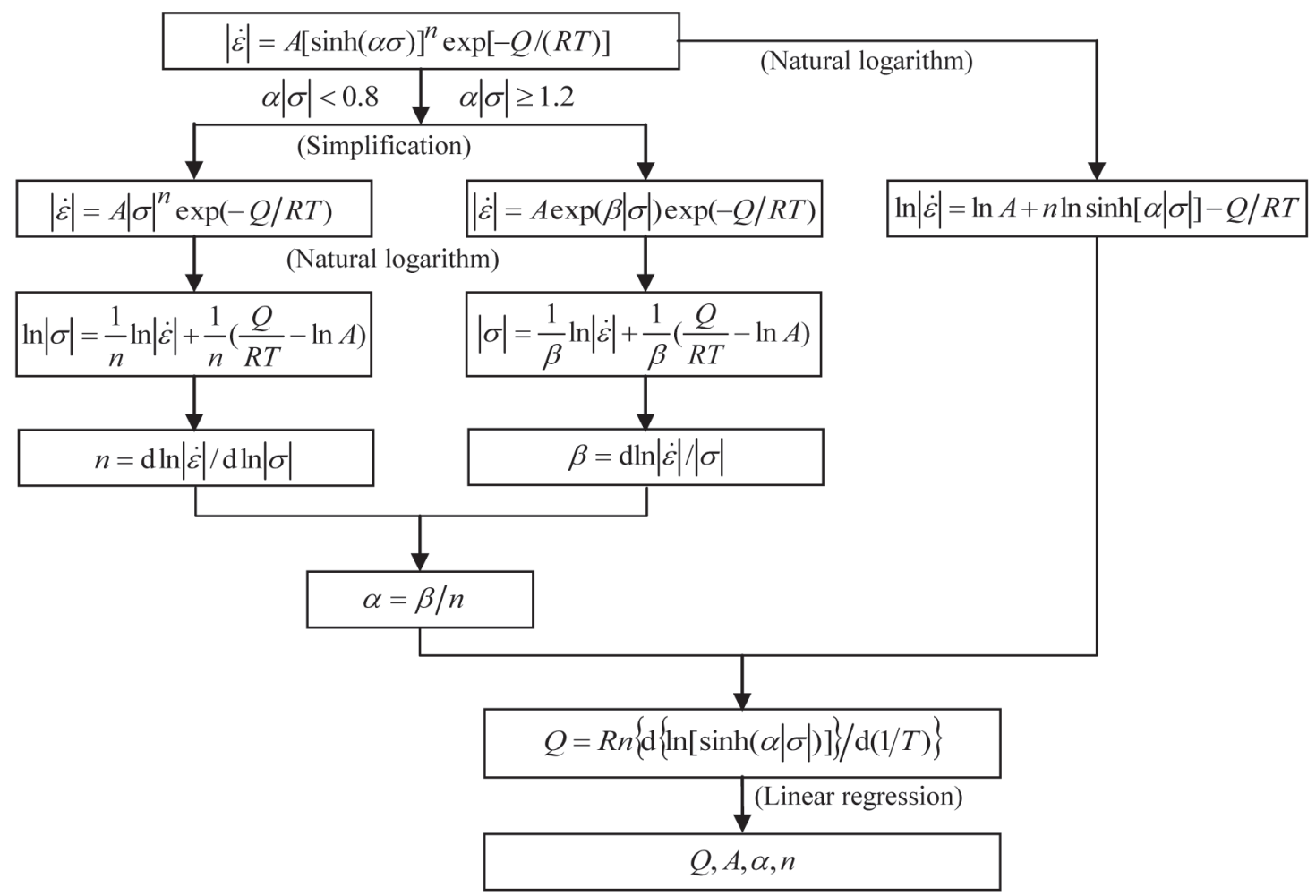

Figure 4. Flow diagram for determining all parameters in constitutive equation. 


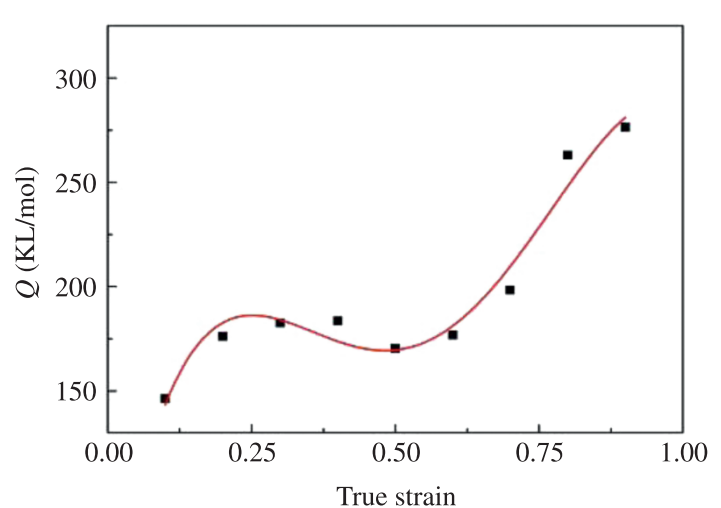

(a)

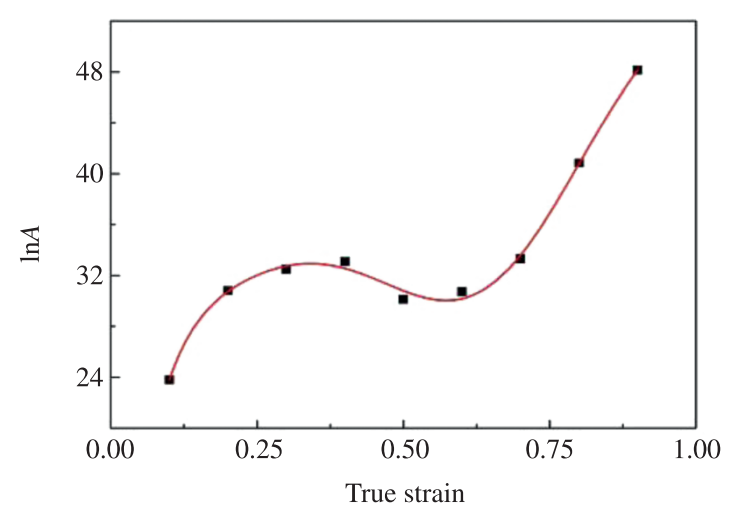

(c)

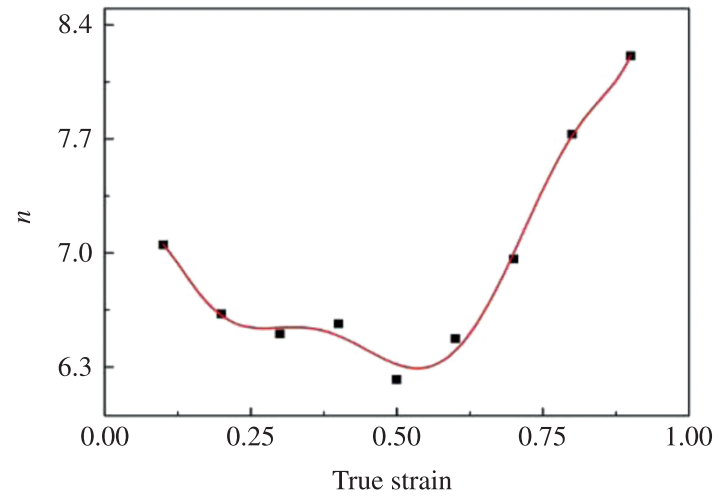

(b)

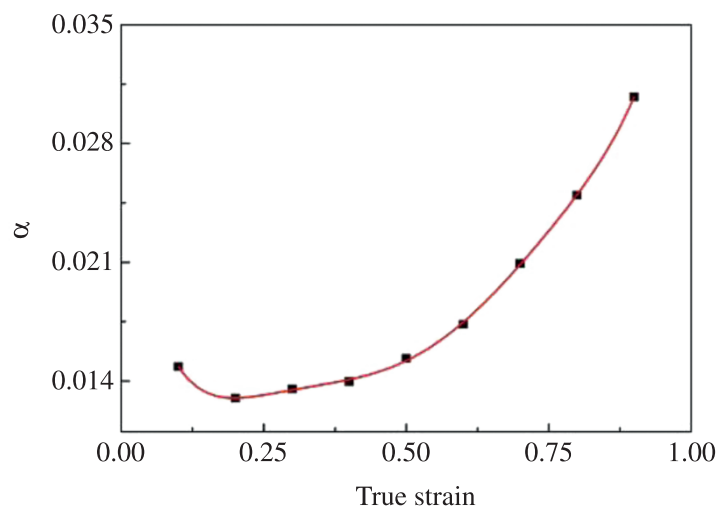

(d)

Figure 5. Relationship between: (a) $Q$; (b) $n$; (c) $\ln A$; (d) $\alpha$ and true strain by polynomial fit of AZ80 magnesium alloy.

Table 1. Polynomial fitting results of $Q, n, \ln A$ and $\alpha$ of as-casting AZ80 magnesium alloy.

\begin{tabular}{cccccccc}
\hline & $\boldsymbol{Q}$ & & $\boldsymbol{n}$ & \multicolumn{1}{c}{$\ln \boldsymbol{A}$} & $\alpha$ \\
\hline$B_{0}$ & 127.6204 & $C_{0}$ & 5.893974 & $D_{0}$ & -7.41621 & $E_{0}$ & 0.0676 \\
$B_{1}$ & -280.9 & $C_{1}$ & 41.83431 & $D_{1}$ & 593.379 & $E_{1}$ & -1.22327 \\
$B_{2}$ & 8664.941 & $C_{2}$ & -505.224 & $D_{2}$ & -4117.87 & $E_{2}$ & 10.73411 \\
$B_{3}$ & -53118.6 & $C_{3}$ & 2644.852 & $D_{3}$ & 16415.46 & $E_{3}$ & -48.3546 \\
$B_{4}$ & 156794.6 & $C_{4}$ & -7163.31 & $D_{4}$ & -38156.6 & $E_{4}$ & 122.0779 \\
$B_{5}$ & -252838 & $C_{5}$ & 10394.41 & $D_{5}$ & 49808.87 & $E_{5}$ & -173.994 \\
$B_{6}$ & 213012.9 & $C_{6}$ & -7637.83 & $D_{6}$ & -33463.5 & $E_{6}$ & 130.5764 \\
$B_{7}$ & -72490.7 & $C_{7}$ & 2230.64 & $D_{7}$ & 8983.701 & $E_{7}$ & -40.0031 \\
\hline
\end{tabular}

$|\sigma|=\frac{1}{e(\varepsilon)} \ln \left\{\left(\frac{\dot{\varepsilon} \mid \exp [b(\varepsilon) / 8.31 T]}{d(\varepsilon)}\right)^{1 / c(\varepsilon)}+\right.$

$\left.\left[\left(\frac{|\dot{\varepsilon}| \exp [b(\varepsilon) / 8.31 T]}{d(\varepsilon)}\right)^{2 / c(\varepsilon)}+1\right]^{1 / 2}\right\}$

\subsection{Verification of the developed constitutive equation}

According to the developed constitutive equation of AZ80 magnesium alloy mentioned above, this model expressing the value of flow stress can be obtained at different strains, temperatures and strain rates. Figure 6 shows the true stress-strain curves obtained from the experiment and predicted results. The range of hot compression conditions corresponds to temperature between $523 \mathrm{~K}$ and $673 \mathrm{~K}$, strain rate between $0.01 \mathrm{~s}^{-1}$ and $10 \mathrm{~s}^{-1}$. It can be seen that the calculated coincide with the measured values is acceptable.

The predictability flow stress of the constitutive equation is also quantified by employing standard statistical parameters such as correlation coefficient $(R)$ and average absolute relative error (AARE). These are expressed by Equation 15 and Equation 16 respectively.

$$
R(\%) \frac{\sum_{N}^{i=1}\left(\left|\sigma_{\mathrm{M} i}\right|-\left|\overline{\sigma_{\mathrm{M}}}\right|\right)\left(\left|\sigma_{\mathrm{p} i}\right|-\left|\overline{\sigma_{\mathrm{p}}}\right|\right)}{\sqrt{\sum_{N}^{i=1}\left(\left|\sigma_{\mathrm{M} i}\right|-\mid \overline{\sigma_{\mathrm{M}}}\right)^{2}} \sum_{N}^{i=1}\left(\left|\sigma_{\mathrm{p} i}\right|-\mid \overline{\sigma_{\mathrm{p}}}\right)^{2}}
$$

$\operatorname{AARE}(\%)=\frac{1}{N} \sum_{i=1}^{N}\left|\frac{\left|\sigma_{\mathrm{M} i}\right|-\left|\sigma_{\mathrm{p} i}\right|}{\left|\sigma_{\mathrm{M} i}\right|} \times 100 \%\right|$

Where $\left|\sigma_{\mathrm{M}}\right|$ is the measured value and $\left|\sigma_{\mathrm{P}}\right|$ is the predicted value obtained from the constitutive equation. $\left|\overline{\sigma_{\mathrm{M}}}\right|$ and $\left|\overline{\sigma_{\mathrm{P}}}\right|$ are the mean values of $\left|\sigma_{\mathrm{M}}\right|$ and $\left|\sigma_{\mathrm{P}}\right|$, respectively. $N$ is the number of data which were employed in the investigation. The correlation coefficient is a commonly used statistical parameter and provides 


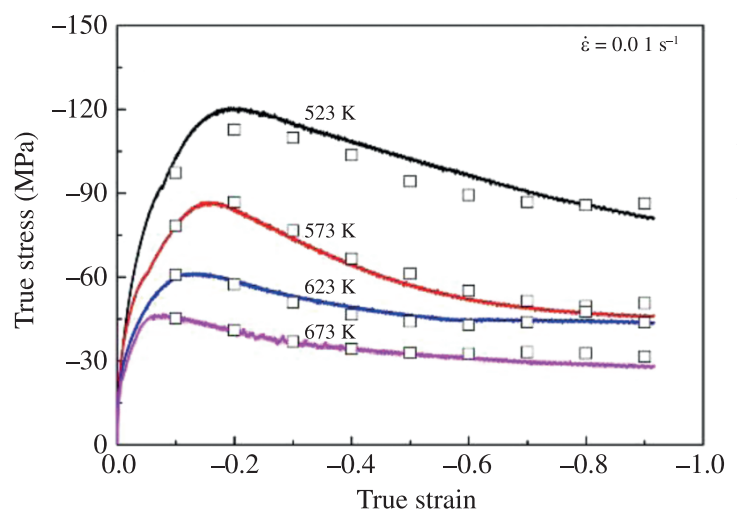

(a)

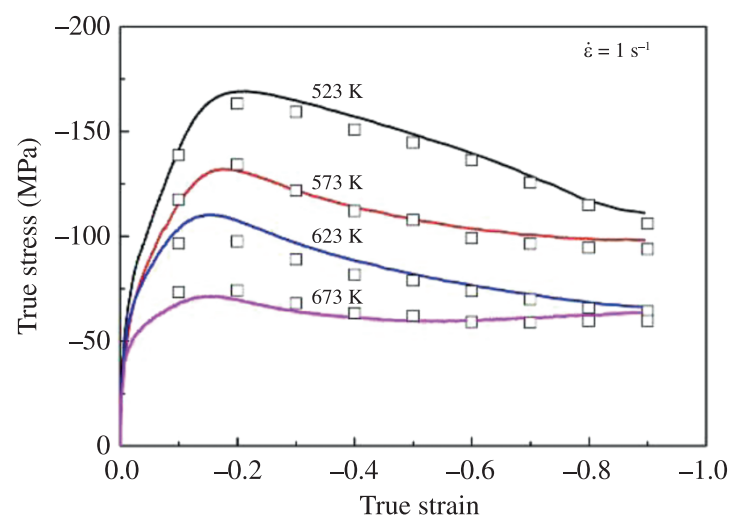

(c)

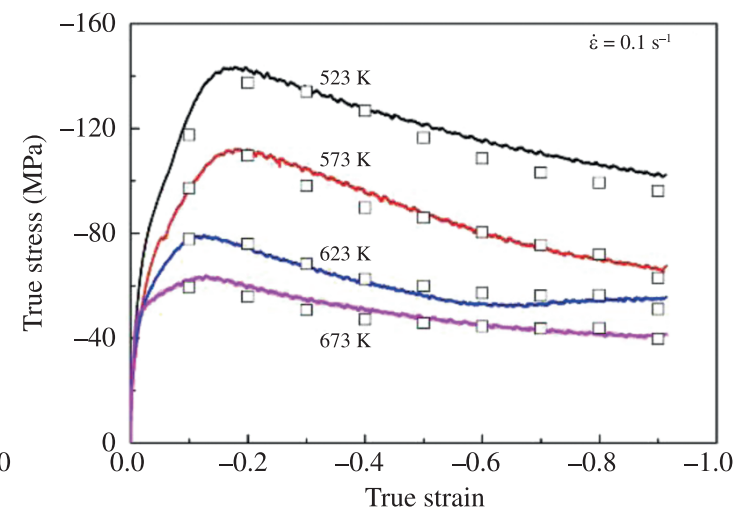

(b)

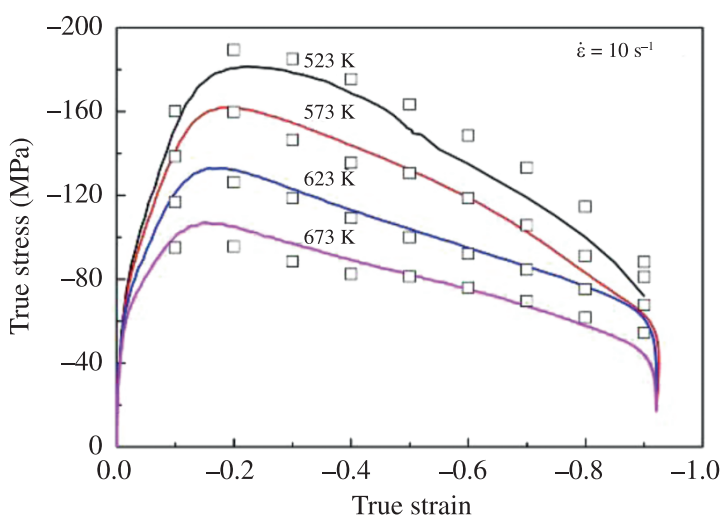

(d)

Figure 6. Comparisons between predicted and measured flow stress curves of AZ80 magnesium alloy under strain rates of: (a) $0.01 \mathrm{~s}^{-1}$; (b) $0.1 \mathrm{~s}^{-1}$; (c) $1 \mathrm{~s}^{-1}$; (d) $10 \mathrm{~s}^{-1}$.

information about the strength of linear relationship between the observed and the calculated values. The AARE is also computed through a term-by-term comparison of the relative error and therefore is an unbiased statistical parameter to measure the predictability of an equation. The value of $R$ and AARE was found to be 0.99 and $6.63 \%$, respectively, which statistical results shows that the developed deformation constitutive equation gives an accurate and precise estimate of the flow stress.

\section{Conclusions}

The constitutive analysis of a cast AZ80 magnesium alloy has been conducted according to a set of hot compression tests. Then Arrhenius equation with ZenerHollomon parameter was developed to incorporate the effect

\section{References}

1. Zhou HT, Li QB, Zhao ZK, Liu ZC, Wen SF and Wang QD. Hot workability characteristics of magnesium alloy AZ80-A study using processing map. Materials Science and Engineering: A. 2010; 527(7-8):2022-2026. http://dx.doi.org/10.1016/j. msea.2009.12.009 of strain on the activation energy $Q$ and material constants $A, n$, and $\alpha$, to describe the relationship of flow stress and strain rate as well as deformation temperature during entire forming history. By comparing the values between the predicted and measured flow stress, the standard statistical parameters such as correlation coefficient and average absolute relative error is 0.99 and $6.63 \%$ respectively. The results manifest that the improved Arrhenius model with variable parameters for the as-cast AZ80 magnesium alloy of flow stress is valid and accurate.

\section{Acknowledgements}

This work was supported by Science and Technology Committee of Chongqing (cstc2009aa3012-1), the Fundamental Research Funds for the Central Universities (Project No. CDJXS12130003).

2. Al-Samman T and Gottstein G. Room temperature formability of a magnesium AZ31 alloy: Examining the role of texture on the deformation mechanisms. Materials Science and Engineering: A. 2008; 488(1-2):406-414. http://dx.doi. org/10.1016/j.msea.2007.11.056

3. Lin YC and Chen XM. A critical review of experimental results and constitutive descriptions for metals and alloys in 
hot working. Materials Design. 2011;32(4):1733-1759. http:// dx.doi.org/10.1016/j.matdes.2010.11.048

4. Jonas J, Sellars CM and Tegart WJ McG. Strength and structure under hot-working conditions. Metallurgical Reviews. 1969; 14:1-24. http://dx.doi. org/10.1179/095066069790138056

5. McQueen HJ and Ryan ND. Constitutive analysis in hot working. Materials Science and Engineering A. 2002; 322:4363. http://dx.doi.org/10.1016/S0921-5093(01)01117-0

6. Mandal S, Rakesh V, Sivaprasad PV, Venugopal S and Kasiviswanathan KV. Constitutive equations to predict high temperature flow stress in a Ti-modified austenitic stainless steel. Materials Science and Engineering: A. 2009; 500(12):114-121. http://dx.doi.org/10.1016/j.msea.2008.09.019

7. Slooff FA, Zhou J, Duszczyk J and Katgerman L. Constitutive analysis of wrought magnesium alloy Mg-Al4-Zn1. Scripta Materialia. 2007; 57:759-762. http://dx.doi.org/10.1016/j. scriptamat.2007.06.023

8. Pu ZJ, Wu KH, Shi J and Zou D. Development of constitutive relationships for the hot deformation of boron microalloying TiAl-Cr-V alloys. Materials Science and Engineering: A. 1995; 192:780-787. http://dx.doi.org/10.1016/09215093(94)03314-5

9. Lin YC, Chen MS and Zhong J. Effect of temperature and strain rate on the compressive deformation behavior of $42 \mathrm{CrMo}$ steel. Journal of Material Processing Technology. 2008; 205(13):308-315. http://dx.doi.org/10.1016/j.jmatprotec.2007.11.113

10. Lin YC, Chen MS and Zhong J. Modeling of flow stress of $42 \mathrm{CrMo}$ steel under hot compression. Materials Science and Engineering: A. 2009; 499(1-2):88-92. http://dx.doi. org/10.1016/j.msea.2007.11.119

11. Lin YC, Chen MS and Zhong J. Constitutive modeling for elevated temperature flow behavior of $42 \mathrm{CrMo}$ steel. Computational Materials Science. 2008; 42(3):470-477. http:// dx.doi.org/10.1016/j.commatsci.2007.08.011
12. Haghdadi N, Zarei-Hanzaki A and Abedi HR. The flow behavior modeling of cast A356 aluminum alloy at elevated temperatures considering the effect of strain. Materials Science and Engineering: A. 2012; 535:252-257. http://dx.doi. org/10.1016/j.msea.2011.12.076

13. Krishnan SA, Phaniraj C, Ravishankar C, Bhaduri AK and Sivaprasad PV. Prediction of high temperature flow stress in $9 \mathrm{Cr}-1 \mathrm{Mo}$ ferritic steel during hot compression. International Journal of Pressure Vessels and Piping. 2011; 88:501-506. http://dx.doi.org/10.1016/j.ijpvp.2011.07.009

14. Shafaat MA, Omidvar H and Fallah B. Prediction of hot compression flow curves of Ti-6Al-4V alloy in $\mathrm{a}+\mathrm{b}$ phase region. Materials and Design. 2011; 32:4689-4695. http:// dx.doi.org/10.1016/j.matdes.2011.06.048

15. Li HY, Wei DD, Hu JD, Li YH and Chen SL. Constitutive modeling for hot deformation behavior of T24 ferritic steel. Computational Materials Science. 2012; 53:425-430. http:// dx.doi.org/10.1016/j.commatsci.2011.08.031

16. Li HY, Wang XF, Wei DD, Hu JD and Li YH. A comparative study on modified Zerilli-Armstrong, Arrhenius-type and artificial neural network models to predict high-temperature deformation behavior in T24 steel. Materials Science and Engineering: A. 2012; 536:216-222. http://dx.doi. org/10.1016/j.msea.2011.12.108

17. Quan GZ, Shi Y, Wang YX, Kang BS, Ku TW and Song WJ, Constitutive modeling for the dynamic recrystallization evolution of AZ80 magnesium alloy based on stress-strain data. Materials Science and Engineering: A. 2011; 528(28):80518059. http://dx.doi.org/10.1016/j.msea.2011.07.064

18. Yue CX, Zhang LW, Liao SL, Pei JB, Gao HJ, Jia YW et al. Research on the dynamic recrystallization behavior of GCr15 steel. Materials Science and Engineering: A. 2009; 499(1-2):177-181. http://dx.doi.org/10.1016/j. msea.2007.11.123 